\title{
The Neuropeptide Y Single-nucleotide Polymorphism rs16147 Moderates the Effect of Alcohol Dependence on Depression
}

\section{Fan Wang}

the Second Affiliated Hospital of Xinjiang Medical University

\section{Siyao Zhou}

Wenzhou Medical University

Li Chen

Wenzhou Medical University

\section{Guanghui Shen}

Wenzhou Medical University

\section{Fan Yang}

Wenzhou Medical University

Huankun Sun

Wenzhou Medical University

Liuzhi Hong

Wenzhou Medical University

\section{Yang Zou}

Wenzhou Medical University

Hui Li

the Second Affiliated Hospital of Xinjiang Medical University

\section{Yu-Hsin Chen}

Wenzhou-Kean University

\section{Yanlong Liu}

Wenzhou Medical University

Wei Wang ( $\square$ wangwei@wmu.edu.cn )

Wenzhou Medical University

\section{Research Article}

Keywords: NPY rs16147, alcohol dependence, depression, interaction

Posted Date: October 22nd, 2021

DOI: https://doi.org/10.21203/rs.3.rs-863544/v1 
License: (c) (i) This work is licensed under a Creative Commons Attribution 4.0 International License. Read Full License 


\section{Abstract}

Background: Previous studies suggest that alcohol dependence is associated with depression, however, the effect of alcohol dependence varies from individual to individual, which may be due to different genetic backgrounds. The interactions between alcohol dependence and different gene polymorphisms may finally shape the onset of depression. Neuropeptide Y (NPY), which can maintain homeostasis from high-stress stimulation, may protect individuals from the onset of depression. Here, we explored whether the NPY rs16147 regulates depression in individuals with alcohol dependence during the period of alcohol dependence withdrawal.

Methods: A total of 455 males with alcohol dependence were recruited. The scale of MAST and SDS were respectively used to analyze the condition of alcohol dependence and depression. Genomic DNA was extracted from each blood sample and NPY polymorphisms were genotyped. The interaction between NPY rs16147 and alcohol dependence on depression was first analyzed. Then, region of significance analysis was used to confirm which model provided the best fit for the interaction (diathesis-stress or differential susceptibility). Finally, by using internal replication analyses, the accuracy and robustness of the interaction results were improved.

Results: Alcohol dependence was positively correlated with depression. CC homozygotes of NPYrs16147 exhibited less depression when exposed to low alcohol dependence, but more depression when exposed to high alcohol dependence. Individuals with the T allele showed the opposite result.

Conclusions: NPY rs16147 might be correlated with susceptibility for depression in males during alcohol dependence withdrawal. The findings support the differential susceptibility model.

\section{Introduction}

Alcohol use is an established facet of diverse cultural contexts and religions, providing perceived pleasure to many users and facilitating social interaction, however, excessive alcohol use is also a principal causal factor in a number of mental health conditions, including alcohol dependence and other alcohol use disorders [1]. According to the WHO global status report on alcohol and health in 2018, alcohol dependence (identified as an impairment of self-control over his or her drinking) is often associated with mental health problems such as depression[2]. Further studies have shown that alcohol dependence significantly increases the risk of suffering from depression $[3,4]$. However, reports on the effect of acute alcohol dependence withdrawal (ADW) and the onset and emergence of depression varies greatly across individuals[5].

The literature on alcohol dependence withdrawal indicates that not all individuals experience symptoms of depression in the context of ADW. Several depression studies indicate that more than $50 \%$ of depression patients have experienced severe adversity before the onset of the illness, while some people facing severe stress never have symptoms of depression[6, 7]. To further investigate factors that lead to differences in the development of depression on an individual level, depression and alcoholism studies 
began to investigate the association of polymorphisms in various genetic regions of alcohol dependent subjects[8-10]. Amongst cyclic AMP (cAMP), protein kinase A(PKA), cAMP responsive element-binding (CREB), and NPY, the role of NPY in the development of depression within the context of alcohol dependence is well-established[8, 10-12]. NPY, a highly conserved 36-residue peptide, is reported to be densely distributed in amygdala, hippocampus, neocortex and other areas related to psychopathology, playing a pivotal role in regulating emotion response[13]. Many studies have shown that the expression level of NPY in the brain is closely related to the occurrence of depression. For example, people with low levels of NPY in the brain have a higher risk of depression[14]. Conversely, administration of NPY have anti-stress effects, and thereby can reduce emotional responses on depression[15]. Previous studies have identified NPY rs16147, a single promoter variant, responsible for the expression of NPY[10]. Furthermore, it reported that NPY rs16147 genotypes were associated with stress experiences, which can predict stress-related outcomes. In animal models, NPY reduces stress effects $[15,16]$ and alcohol consumption[17], and opposes the actions of corticotropin-releasing factor (CRF)[18] as well as responsible for the anxiogenic and stress-like consequences of alcohol dependence withdrawal[11].

Yet to date, few studies have examined the exact form of the interaction between the environment and NPY rs16147 gene polymorphism. According to the literature on Gene-by-environment (GxE) interactions, the interaction between environment and gene polymorphism can be fitted into two model. The diathesisstress model of environmental action[19] suggests individuals with a risk gene are affected negatively by poor environments, whereas individuals with a different version of the same gene are relatively unaffected by environments. Where given the best environments, individuals with differing polymorphisms may exhibit similar levels of behavior, but behavior of the groups diverges with worsening environmental conditions. The differential-susceptibility model [20] on the other hand, suggests that individuals carrying "risk alleles" may simply be more malleable to changes in the environment. Wherein, individuals with a putative high-risk allele should exhibit poorer outcomes in poor environments and similar outcomes to individuals with a low-risk allele in average environments. However, in very good environments, individuals with a putative high-risk allele will show outcomes that are superior to individuals with the low-risk allele. In other words, individuals with "risk alleles" are malleable to environment conditions, benefitting from supportive environments but exhibiting poorer outcomes in poor environments.

The present study aims to understand the role of NPY rs16147 on depression in patients with acute alcohol dependence withdrawal. According to the literature on alcohol dependence and depression, NPY rs16147 is key to understanding the development of depression in alcohol dependence withdrawal population[21]. Yet to date, the exact form of the interaction between the environment and NPY rs16147 gene polymorphism remains unclear. To further understand the role of NPY rs16147, blood samples and scores of Michigan Alcoholism Screening Test (MAST), Self-Depression Scale (SDS) were obtained from alcohol dependence patients from seven psychiatric hospitals. Confirmatory analytic approaches commonly used in previous studies were then conducted to identify the form of GxE interaction. Specifically to identify whether the role of NPY rs16147 conforms to the diathesis-stress model or the differential-susceptibility model. Based on the current literature suggesting that T alleles of rs16147 are 
protective under high stress conditions[10]. It could be hypothesized that NPY rs16147 may accord with the differential-susceptibility model, wherein NPY rs16147 under very good environment conditions may show outcomes that are superior to individuals with the low-risk allele; but poorer outcomes in poor environments and similar outcomes in average environments compared to low-risk allele.

\section{Methods}

\subsection{Participants}

A total of 455 males were recruited from seven psychiatric hospitals in northern China: Beijing Hui Long Guan Hospital, Shandong Mental Health Center, the Sixth Hospital in Changchun, Shenyang Mental Health Center, the Third Hospital in Inner Mongolia Autonomous Region, Hulunbuir Mental Health Center, and Tongliao Mental Health Center. All the patients recruited in the study met the criteria for alcohol dependence based on the Structured Clinical Interview for DSM-IV Axis I disorders(SCID).

The inclusion criteria were as follows: 1 ) diagnosis of alcohol dependence according to the DSM-IV; 2 ) Han ethnicity; 3 ) provided written informed consent. The exclusion criteria were as follows: 1) presence of other substance abuse or dependence; 2) presence of severe cardiovascular disease, liver disease, or kidney disease; 3 ) participant, or a first-degree relative of the participant, has a serious mental illness; 4) individual declined to participate.

The participants were asked to complete a series of questionnaires and provide a blood sample for DNA extraction. All staff involved in this study were trained before the study commenced.

\subsection{Measures}

\subsubsection{Alcohol dependence}

Alcohol dependence was assessed using MAST[8]. The MAST is a self-report questionnaire comprising 25 items rated on a scale from 1 to 4 , with a higher number corresponding to greater alcohol dependence. The scale has high internal consistency reliability, with an alpha value of $0.90[10]$.

\subsubsection{Depression}

SDS was used to assess each participant's level of depression. The SDS contains 20 items that are rated on a scale from 1 to 4 , with higher numbers corresponding to more frequent symptoms. The higher the total score, the more severe the depressive symptoms[12].

\subsection{Genotyping}

Genomic DNA was extracted from each blood sample using standard techniques. The NPY polymorphisms were genotyped using 5'nuclease fluorescent TaqManTM primer (Applied Biosystems, Foster City, CA)

\subsection{Statistical analysis}


First, the Hardy-Weinberg equilibrium for genotype distributions of NPY rs16147 was tested using the c2 test for goodness of fit. Then, pearson correlations were examined between genetic polymorphisms, age, years of education, alcohol dependence, and depression. Consistent with other research, CT and TT genotypes were collapsed into a T-allele group and coded as 1 ; the CC genotype was coded as 0 . Then, traditional linear regression was used to test the interaction between alcohol dependence and the rs16147 polymorphism. When a significant interaction was found, region of significance (RoS) analysis was used to examine the form of the interaction[22].

Finally, a re-parameterized regression model was fitted to examine the specific pattern of gene xenvironment pattern[23], which had the form :

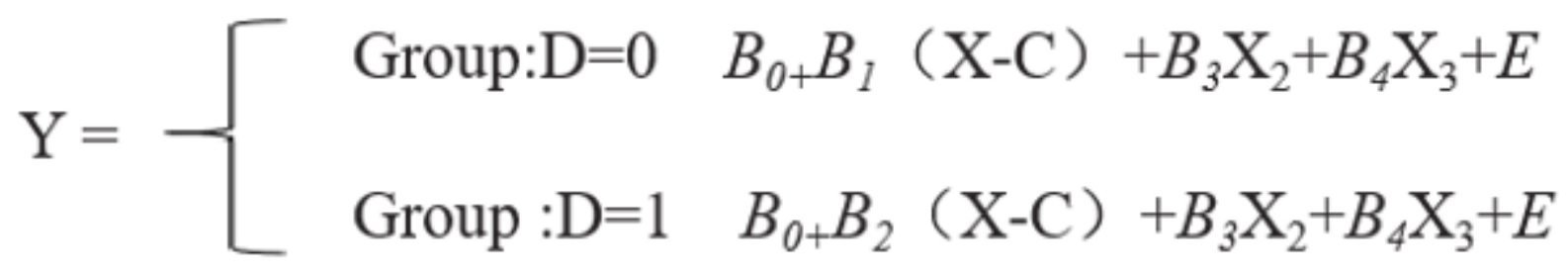

Where Group is the allelic group, $\mathrm{X}$ is alcohol dependence, $\mathrm{X} 2$ and $\mathrm{X} 3$ are the demographic covariates age and years of education, $Y$ is the dependent variable of depression, and $C$ is the crossover point where the slopes of the different groups cross. What distinguishes the diathesis-stress model and differential susceptibility model is the estimate and interval estimate of crossover point $\mathrm{C}$. If the estimate and interval estimate of crossover point $\mathrm{C}$ fall within the range of alcohol dependence, the model is consistent with the differential susceptibility model. Otherwise, if crossover point $C$ is over the maximum of alcohol dependence, the model is consistent with the diathesis-stress model.

The diathesis-stress model and differential susceptibility model can be further subdivided into "strong" and "weak" versions. Strong versions assume that "non-risk/non-plasticity allele" carriers are not susceptible to the environment. Weak versions assume that both allele carriers are susceptible to the environment but "non-risk/non-plasticity allele" carriers are less susceptible to the environment than "risk/plasticity allele" carriers. These models are nested within each other. Thus, the F test was used to compare the models and identify a difference in the parameter estimates. For non-nested models, the Akaike information criterion (AIC) and Bayesian information criterion (BIC) were compared to evaluate which model was a better fit.

\section{Results}

\subsection{Descriptive statistics}

Table 1 showed the demographic and clinical characteristics of the participants. The mean age of the participants was 44.31 years $(S D=9.29)$. Regarding their education, the average number of years in formal schooling was 10.69 (SD = 2.84). And the mean scores of MAST was 9.28(SD=5.47) and SDS 
was 56.06(SD=11.39). The condition of marital status and living patterns were also listed in the table. Besides, of the 455 male inpatients, 60 (13.19\%) were CC homozygotes, 213 (46.81\%) were CT heterozygotes, and 182 (40.00\%) were TT homozygotes. The genotype distribution of NPY rs16147 was consistent with the Hardy-Weinberg equilibrium $(\chi 2=0.04, p>0.05$, Table 2$)$. A series of $t$ tests were then conducted to examine whether male inpatients with and without alcohol dependence and depressive symptoms differed in terms of the polymorphism NPY rs16147. The results revealed no significant differences (alcohol dependence: $t=1.13$; depression: $t=0.11$, both $p>0.05$, Table 3 ).

Table 1

Demographic and clinical characteristics of the participants $(\mathrm{N}=455)$.

\begin{tabular}{ll} 
Factors & Mean (SD) or N (\%) \\
\hline Age & $44.31(9.29)$ \\
\hline Education years & $10.69(2.84)$ \\
\hline Marital status & \\
\hline Married & $328(72.1 \%)$ \\
\hline Not married & $51(11.2 \%)$ \\
\hline Divorced & $70(15.4 \%)$ \\
\hline Widowed & $6(1.3 \%)$ \\
\hline Living patterns & \\
\hline Live with family & $361(79.3 \%)$ \\
\hline Living with non-family & $94(20.7 \%)$ \\
\hline MAST & $9.28(5.47)$ \\
\hline SDS & $56.06(11.39)$ \\
\hline Note: MAST=the Michigan Alcoholism Screening Test; SDS= The Self-rating Depression Scale
\end{tabular}

Table 2

Hardy-Weinberg equilibrium 


\begin{tabular}{|lll|}
\hline Genotype & Number of people & Percentage \\
\hline CC & 60 & 13.19 \\
\hline CT & 213 & 46.81 \\
\hline TT & 182 & 40.00 \\
\hline$X^{2}$ & $0.04 \quad p$ & 0.85 \\
\hline
\end{tabular}

Table 3

Independent sample test

\begin{tabular}{|lll|}
\hline NPY rs16147 & Alcohol Dependence & Depression \\
\hline CC homozygote & $10.02 \varangle 5.70 \rrbracket$ & $56.22 \rrbracket 14.60 \rrbracket$ \\
\hline T allele & $9.16 \rrbracket 5.43 \rrbracket$ & $56.04 \rrbracket 10.84 \rrbracket$ \\
\hline$t$ & 1.13 & 0.11 \\
$p$ & 0.26 & 0.93 \\
\hline
\end{tabular}

\subsection{Correlation of MAST and SDS scores}

The descriptive statistics for each research variable are shown in Table 4. Male inpatients' MAST scores were positively correlated with SDS scores $(r=0.24, p<0.01)$. Whilst MAST scores were negatively correlated with the educational years $(r=-0.2, p<0.01)$. No significant correlation between polymorphisms of NPY rs16147 and MAST ( $p>0.05)$, as well as SDS scores $(p>0.05)$ were observed.

Table 4

Descriptive statistics and correlations among study variables 


\begin{tabular}{|c|c|c|c|c|c|}
\hline & $\begin{array}{l}\text { NPY } \\
\text { rs16147 }\end{array}$ & Age & $\begin{array}{l}\text { Educational } \\
\text { Years }\end{array}$ & $\begin{array}{l}\text { Alcohol } \\
\text { Dependence }\end{array}$ & Depression \\
\hline NPY rs16147 & 1 & & & & \\
\hline Age & 0.01 & 1 & & & \\
\hline Educational Years & -0.02 & $-0.38^{\star \star}$ & 1 & & \\
\hline $\begin{array}{l}\text { Alcohol } \\
\text { Dependence }\end{array}$ & -0.05 & $0.15^{\star \star}$ & $-0.20^{\star \star \star}$ & 1 & \\
\hline Depression & -0.01 & -0.01 & -0.03 & $0.24^{\star \star \star}$ & 1 \\
\hline$M$ & $(-)$ & 44.31 & 10.69 & 9.28 & 56.06 \\
\hline$S D$ & $(-)$ & 9.29 & 2.84 & 5.47 & 11.39 \\
\hline
\end{tabular}

\subsection{Effect of interactions between NPY genotyping and alcohol dependence on depression}

Next, hierarchical regression models were used to predict depression from alcohol dependence for different allelic groups, with age and years of education as covariates. With regard to the main effects, Table 5 shows that alcohol dependence was positively related to depressive symptoms $(\beta=0.52, p<$ $0.05)$, but that there was no main effect of genotype $(\beta=-0.02, p=0.65)$. Furthermore, the interaction between NPY rs16147 and alcohol dependence was significant $(\beta=-0.29, p<0.05)$. Then, the RoS test was used to examine the interaction effect. As shown in Figure 1, the slopes for alcohol dependence on depression were as follows: CC homozygotes, $\beta=0.25, t=16.44, p<0.01$; T allele carriers, $\beta=0.23, t=$ $4.90, p<0.01$. Relative to T allele carriers, CC homozygotes were more likely to be affected by alcohol dependence causing depression.

Table 5

Interaction between NPY rs16147 and alcohol dependence on depression during acute alcohol dependence withdrawal 


\begin{tabular}{|c|c|c|c|c|c|c|}
\hline \multirow[t]{2}{*}{ Variables } & \multicolumn{6}{|c|}{ Depression } \\
\hline & $\Delta R^{2}$ & $B \square S E \square$ & $\beta$ & $t$ & $p$ & $\begin{array}{l}95 \% \text { Confidence } \\
\text { Interval }\end{array}$ \\
\hline Age & \multirow[t]{2}{*}{0.01} & $\begin{array}{l}0.01 \\
\otimes 0.01 \rrbracket\end{array}$ & 0.05 & 0.92 & 0.36 & -0.01 to 0.02 \\
\hline Educational Years & & 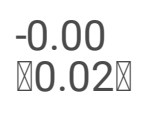 & -0.01 & -0.11 & 0.91 & -0.04 to 0.03 \\
\hline Alcohol Dependence & \multirow[t]{2}{*}{0.05} & $\begin{array}{l}0.52 \\
\otimes 0.12 \rrbracket\end{array}$ & 0.52 & 4.29 & $<0.001^{\star \star \star}$ & 0.28 to 0.76 \\
\hline NPY rs16147 & & 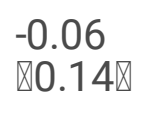 & -0.02 & -0.45 & 0.65 & -0.33 to 0.21 \\
\hline $\begin{array}{l}\text { Alcohol } \\
\text { Dependencex NPYrs16147 }\end{array}$ & 0.01 & 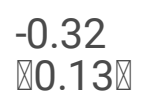 & -0.29 & -2.41 & $0.02^{*}$ & -0.57 to -0.06 \\
\hline Note $\mathbb{N} N Y=$ Neuropeptide $Y$ & $.05 \rrbracket^{* *}$ & 0.01 & .00 & & & \\
\hline
\end{tabular}

\subsection{Internal Replication Analyses}

In order to improve the accuracy and robustness of the interaction results, re-parameterized regression model was fitted to examine the specific pattern of genex environment. The fit of the weak differential susceptibility model, Model $B$, yielded a significant $R^{2}=0.07, p<0.001$ (Table 6), explained a significant amount of variance in depression, in which the slope for T allele group was significant $\left(B_{2}=0.52, p<\right.$ 0.001). The estimated crossover point $\mathrm{C}$ and $95 \% \mathrm{Cl}$ of $\mathrm{C}$ both fell within the range of alcohol dependence, $\mathrm{C}=-0.19$ ( $\mathrm{SE}=0.43), 95 \% \mathrm{Cl}=[-1.03,0.65]$. Thus, Model $\mathrm{B}$ provides strong support for the weak differential susceptibility model, indicating that the $T$ allele carriers with alcohol dependence is less susceptible to depression than CC homozygotes.

Table 6

Results for re-parameterized regression model for depression 


\begin{tabular}{|c|c|c|c|c|}
\hline \multirow[b]{2}{*}{ Parameter } & \multicolumn{2}{|c|}{ Differential susceptibility } & \multicolumn{2}{|c|}{ Diathesis-stress } \\
\hline & Strong $\rrbracket$ & Weak》 & Strong $\rrbracket$ & Weak》 \\
\hline & Model A & Model B & Mode C & Mode D \\
\hline$B_{0}$ & $-0.21 \varangle 0.36 \rrbracket$ & $-0.24 \rrbracket 0.37 \rrbracket$ & $-0.22 \llbracket 0.36 \rrbracket$ & $0.15 \llbracket 0.36 \rrbracket$ \\
\hline \multirow[t]{2}{*}{$B_{1}$} & $0.00 \rrbracket-\rrbracket$ & $0.21^{\star \star \star}$ & $0.00 \nabla-\nabla$ & $0.24^{\star \star \star}$ \\
\hline & & $₫ 0.05 \rrbracket$ & & $\nabla 0.05 \rrbracket$ \\
\hline C & $-0.10 \otimes 0.27 \rrbracket$ & $-0.19 \otimes 0.43 \rrbracket$ & $1.51 \rrbracket--\rrbracket$ & $1.51 \rrbracket--\bigotimes$ \\
\hline $95 \% \mathrm{Cl}$ of $\mathrm{C}$ & {$[-0.63,0.43]$} & {$[-1.03,0.65]$} & $\nabla--\square$ & $\nabla-\square$ \\
\hline \multirow[t]{2}{*}{$B_{2}$} & $0.51^{\star \star \star}$ & $0.52^{\star \star \star}$ & $0.17^{\star \star \star}$ & $0.32^{\star \star \star}$ \\
\hline & $\triangle 0.12 \rrbracket$ & $₫ 0.12 \rrbracket$ & $\otimes 0.07 \rrbracket$ & $\nabla 0.07 \rrbracket$ \\
\hline$B_{3}$ & $0.01 \otimes 0.01 \rrbracket$ & $0.01 \otimes 0.01 \rrbracket$ & $0.01 \rrbracket 0.01 \rrbracket$ & $0.01 \rrbracket 0.01 \rrbracket$ \\
\hline$B_{4}$ & $0.01 \rrbracket 0.02 \rrbracket$ & $-0.01 \otimes 0.02 \rrbracket$ & $0.01 \rrbracket 0.02 \rrbracket$ & $-0.00 \rrbracket 0.02 \rrbracket$ \\
\hline$R^{2}$ & 0.04 & 0.07 & 0.01 & 0.06 \\
\hline$F$ & $4.48^{\star \star \star}$ & $8.90^{\star \star \star}$ & 2.11 & $7.68^{\star \star \star}$ \\
\hline$\square d f \square$ & $\varangle 4,450 \rrbracket$ & $₫ 5,449 \rrbracket$ & $\llbracket 3,451 \rrbracket$ & $₫ 4,450 \rrbracket$ \\
\hline$F v s . A(d f)$ & $\mathbb{D}-\mathbb{\square}$ & $16.98^{\star \star \star}$ & $11.41^{\star \star \star}$ & $\nabla-\otimes$ \\
\hline$F v s . B(d f)$ & $16.98^{\star \star \star}$ & $\nabla-\nabla$ & $14.40^{\star \star \star}$ & $4.56^{*}$ \\
\hline AIC & 1284.47 & 1269.58 & 1293.87 & 1272.19 \\
\hline $\mathrm{BIC}$ & 1309.19 & 1298.42 & 1314.47 & 1296.91 \\
\hline
\end{tabular}

\section{Discussion}

Alcohol dependence withdrawal can be regarded as an acute stressor, and NPY is conducive to coping with stress-related psychological disorders. Thus, the purpose of this study was to explore the interaction between alcohol dependence and NPY rs16147 and its role in the occurrence of depression during the period of $A D W$. The results revealed that during the period of $A D W$, when the degree of alcohol dependence was low, NPY rs16147 CC homozygotes showed a lower degree of depression compared 
with those who carried the NPY rs16147 T allele. When the degree of alcohol dependence was high, the result was reversed. Further, the model conformed to the differential susceptibility model.

We firstly identified the role of the NPY rs $16147 \times$ alcohol dependence interaction in depression and then competitive model-testing analysis was employed to evaluate which gene and disease interaction model was the best fit for the data. The results revealed that the weak differential susceptibility model was the best fit. This indicates that $\mathrm{CC}$ homozygotes react differently to depression in the adverse or positive condition of alcohol dependence during the period of ADW. Individual genetic variation and the interactions between genes and external factors may characterize neural circuits and neurochemical functions, which represent the psychological strength of adaptable individuals. Stress-related events (such as ADW) can increase an individual's susceptibility to serious psychiatric problems such as depression. Considering that genetic factors contribute to recovery, it is necessary to identify candidate genetic variations to explain genetic patterns.

Alcohol dependence withdrawal can give rise to increased CRF synthesis and release[24]. CRF is a stresspromoting neuropeptide which is dysregulated by long-term high-dose alcohol exposure. It can induce anxiogenic behaviors or other stress-related symptoms[18]. Interestingly, NPY and CRF show high neuroanatomical overlap but opposite function[25]. The current researches have consistently pointed out that NPY mainly counteracts alcoholism anxiety and stress-related symptoms caused by CRF in alcohol dependence[18], which suggests the effect of NPY on emotional homeostasis.

The expression of NPY is related to the polymorphism of the NPY gene as well as change in NPY expression. Single nucleotide polymorphisms (SNPs) are genetic variations of nucleotides that may be of functional significance. For the NPY gene, one of the main genetic variations is rs16147, which is located in the promoter region upstream of the NPY gene[26]. The results of this study suggest that rs16147 may play a role in the regulation of emotions, especially in terms of an interaction with alcohol dependence. In relation to the underlying internal mechanisms, there are still some unknowns. Even though, existing researches show that $\mathrm{CC}$ homozygotes is associated with stress-related psychopathology[27]; thus, the current findings may be explained by the fact that individuals with genetic variation respond differently to different degrees of alcohol dependence. Zhou et al. found that healthy individuals with low NPY expression genotypes and $\mathrm{CC}$ homozygotes had increased amygdala activity during the stress response [28]. Depression is associated with an increased response to negative stimuli in the amygdala. When the degree of alcohol dependence is increased, the amygdala activity in CC homozygotes may be enhanced. This may explain why CC homozygotes are more likely to be depressed in an adverse environment. Additionally, the current results indicated that individuals with the T allele exhibited about the same amount of depression in the case of severe alcohol dependence and in the condition of mild alcohol dependence. This finding aroused our interest. It has been reported that NPY rs16147 can interact with chronic stress and affect autonomic control, of which the T genotype is associated with vagal activity. Under high chronic stress, vagus nerve activity was found to be increased in patients with the T genotype[29]. Thus, it may be that with an increased degree of alcohol dependence, $T$ allele carriers can increase their capacity to cope with depression by regulating the levels of vagal activity. 
These findings shed light on the potential mechanism of NPY rs16147 in depression during ADW. According to the mechanism of genetic susceptibility, individuals of different genotypes showed different characteristics under stress. The early adverse environment may change the concentration of NPY, which can further induce stress-related psychopathology for some genotypes. Moreover, for some individuals, genetic resilience may enable the generation of more psychological resources in the face of adverse environmental stressors. In the current study, T allele carriers were able to adjust their state of emotion when dealing with adverse alcohol dependence, while CC homozygotes may have trouble dealing with a bad mood when experiencing severe alcohol dependence.

These findings provide some guidance for the prevention of depression during alcohol withdrawal for individuals with alcohol dependence. Firstly, in the case of high-risk individuals (CC homozygotes), we can intervene in advance so as to prevent exacerbation of depression; for individuals with the T allele, we can enhance their ability to adjust themselves when facing adverse environments. A systematic review of the factors associated with relapse of alcohol use indicated that emotion change can lead to alcohol dependence relapse[30]. Therefore, in the long run, the probability of recurrence of alcohol dependence can be reduced by improving depressive symptoms during ADW.

Several limitations of this study should be addressed. First, this study focused on male Chinese individuals, which may not be generalizable to the Chinese population. Second, as a cross-sectional study, the emotion and alcohol dependence status of the participants were only measured once; thus, the long-term association between depression and alcohol dependence among participants with different genotypes could not be detected. Third, the data were collected using self-rating scales, so there may be reporting bias.

In conclusion, there was an interaction between NPY rs16147 and alcohol dependence indicating that rs16147 might correlate with susceptibility for depressive symptoms among male adults with alcohol dependence during the period of ADW. These findings provide support for the differential susceptibility model, in which the CC homozygote of rs 16147 was a plasticity factor rather than a factor that only increased the depression symptoms of individuals during ADW. These empirical findings have important implications for understanding the genetic moderation of alcohol dependence and its effect on individual differences in depression symptoms during the period of ADW. Further work is required to explore the underlying mechanisms of depression modulation at the molecular level, especially in relation to functional studies of neural systems.

\section{Abbreviations}

NPY Neuropeptide Y

ADW Alcohol Dependence Withdrawal

CAMP AMP 
PKA protein kinase $A$

CREB cAMP responsive element-binding

CRF corticotropin-releasing factor

GxE Gene-by-environment

MAST Michigan Alcoholism Screening Test

SDS Self-Depression Scale

RoS region of significance

\section{Declarations}

\section{Ethics approval and consent to participate}

The study was approved by the Ethics Committee of Peking University Health Science Center. All patients provided written informed consent and were told that the blood sample was to be subjected to a gene assay. All methods were carried out in accordance with relevant guidelines and regulations.

\section{Consent for publication}

Not applicable

\section{Availability of data and materials}

All data generated or analysed during this study are included in this published article and its supplementary information files.

\section{Competing interests}

The authors declare that they have no competing interests

\section{Funding}

This work was supported by the [Natural Science Foundation of Xinjiang Province] under Grant [2018D01C239]; [the Science and Technology Program of Wenzhou] under Grant [Y20190098].

\section{References}


1. Peacock A, Leung J, Larney S, Colledge S, Hickman M, Rehm J, Giovino GA, West R, Hall W, Griffiths P et al: Global statistics on alcohol, tobacco and illicit drug use: 2017 status report. Addiction 2018, 113(10):1905-1926.

2. Group AaPP: Alcohol: no ordinary commodity-a summary of the second edition. Addiction 2010, 105(5):769-779.

3. Agabio R, Trogu E, Pani PP: Antidepressants for the treatment of people with co-occurring depression and alcohol dependence. Cochrane Database Syst Rev 2018, 4(4):Cd008581.

4. Boden JM, Fergusson DM: Alcohol and depression. Addiction 2011, 106(5):906-914.

5. Prescott CA, Cross RJ, Kuhn JW, Horn JL, Kendler KS: Is risk for alcoholism mediated by individual differences in drinking motivations? Alcohol Clin Exp Res 2004, 28(1):29-39.

6. Nestler EJ, Landsman D: Learning about addiction from the genome. Nature 2001, 409(6822):834835.

7. Elisei S, Sciarma T, Verdolini N, Anastasi S: Resilience and depressive disorders. Psychiatr Danub 2013, 25 Suppl 2:S263-267.

8. Opalach C, Romaszko J, Jaracz M, Kuchta R, Borkowska A, Buciński A: Coping Styles and Alcohol Dependence among Homeless People. PLoS One 2016, 11(9):e0162381.

9. Procopio DO, Saba LM, Walter H, Lesch O, Skala K, Schlaff G, Vanderlinden L, Clapp P, Hoffman PL, Tabakoff B: Genetic markers of comorbid depression and alcoholism in women. Alcohol Clin Exp Res 2013, 37(6):896-904.

10. Skinner HA, Sheu WJ: Reliability of alcohol use indices. The Lifetime Drinking History and the MAST. J Stud Alcohol 1982, 43(11):1157-1170.

11. Pucci M, Micioni Di Bonaventura MV, Wille-Bille A, Fernández MS, Maccarrone M, Pautassi RM, Cifani C, D'Addario C: Environmental stressors and alcoholism development: Focus on molecular targets and their epigenetic regulation. Neurosci Biobehav Rev 2019, 106:165-181.

12. Zung WW, Richards $C B$, Short MJ: Self-rating depression scale in an outpatient clinic. Further validation of the SDS. Arch Gen Psychiatry 1965, 13(6):508-515.

13. Eaton K, Sallee FR, Sah R: Relevance of neuropeptide Y (NPY) in psychiatry. Curr Top Med Chem 2007, 7(17):1645-1659.

14. Mickey BJ, Zhou Z, Heitzeg MM, Heinz E, Hodgkinson CA, Hsu DT, Langenecker SA, Love TM, Peciña $M$, Shafir $T$ et al: Emotion processing, major depression, and functional genetic variation of neuropeptide Y. Arch Gen Psychiatry 2011, 68(2):158-166.

15. Heilig M: The NPY system in stress, anxiety and depression. Neuropeptides 2004, 38(4):213-224.

16. Heilig M, Wahlestedt C, Widerlöv E: Neuropeptide Y (NPY)-induced suppression of activity in the rat: evidence for NPY receptor heterogeneity and for interaction with alpha-adrenoceptors. Eur $J$ Pharmacol 1988, 157(2-3):205-213.

17. Pleil KE, Rinker JA, Lowery-Gionta EG, Mazzone CM, McCall NM, Kendra AM, Olson DP, Lowell BB, Grant KA, Thiele TE et al: NPY signaling inhibits extended amygdala CRF neurons to suppress binge 
alcohol drinking. Nat Neurosci 2015, 18(4):545-552.

18. Sajdyk TJ, Shekhar A, Gehlert DR: Interactions between NPY and CRF in the amygdala to regulate emotionality. Neuropeptides 2004, 38(4):225-234.

19. Burmeister M, McInnis MG, Zöllner S: Psychiatric genetics: progress amid controversy. Nat Rev Genet 2008, 9(7):527-540.

20. Belsky J, Pluess M: Beyond diathesis stress: differential susceptibility to environmental influences. Psychol Bull 2009, 135(6):885-908.

21. Thorsell A: Neuropeptide Y (NPY) in alcohol intake and dependence. Peptides 2007, 28(2):480-483.

22. Roisman GI, Newman DA, Fraley RC, Haltigan JD, Groh AM, Haydon KC: Distinguishing differential susceptibility from diathesis-stress: recommendations for evaluating interaction effects. Dev Psychopathol 2012, 24(2):389-409.

23. Belsky J, Pluess M, Widaman KF: Confirmatory and competitive evaluation of alternative geneenvironment interaction hypotheses. J Child Psychol Psychiatry 2013, 54(10):1135-1143.

24. Roberto M, Cruz MT, Gilpin NW, Sabino V, Schweitzer P, Bajo M, Cottone P, Madamba SG, Stouffer DG, Zorrilla EP et al: Corticotropin releasing factor-induced amygdala gamma-aminobutyric Acid release plays a key role in alcohol dependence. Biol Psychiatry 2010, 67(9):831-839.

25. Gilpin NW: Corticotropin-releasing factor (CRF) and neuropeptide Y (NPY): effects on inhibitory transmission in central amygdala, and anxiety- \& alcohol-related behaviors. Alcohol2012, 46(4):329-337.

26. Domschke K, Hohoff C, Jacob C, Maier W, Fritze J, Bandelow B, Krakowitzky P, Kästner F, Rothermundt $\mathrm{M}$, Arolt $\mathrm{V}$ et al: Chromosome 4q31-34 panic disorder risk locus: association of neuropeptide Y Y5 receptor variants. Am J Med Genet B Neuropsychiatr Genet 2008, 147b(4):510516.

27. Sommer WH, Lidström J, Sun H, Passer D, Eskay R, Parker SC, Witt SH, Zimmermann US, Nieratschker $\mathrm{V}$, Rietschel $\mathrm{M}$ et al: Human NPY promoter variation rs16147:T $>\mathrm{C}$ as a moderator of prefrontal NPY gene expression and negative affect. Hum Mutat 2010, 31(8):E1594-1608.

28. Zhou Z, Zhu G, Hariri AR, Enoch MA, Scott D, Sinha R, Virkkunen M, Mash DC, Lipsky RH, Hu XZ et al: Genetic variation in human NPY expression affects stress response and emotion. Nature 2008, 452(7190):997-1001.

29. Chang HA, Fang WH, Chang TC, Huang SY, Chang CC: Association of neuropeptide Y promoter polymorphism (rs16147) with perceived stress and cardiac vagal outflow in humans. Sci Rep 2016, 6:31683.

30. Sliedrecht W, de Waart R, Witkiewitz K, Roozen HG: Alcohol use disorder relapse factors: A systematic review. Psychiatry Res 2019, 278:97-115.

\section{Figures}




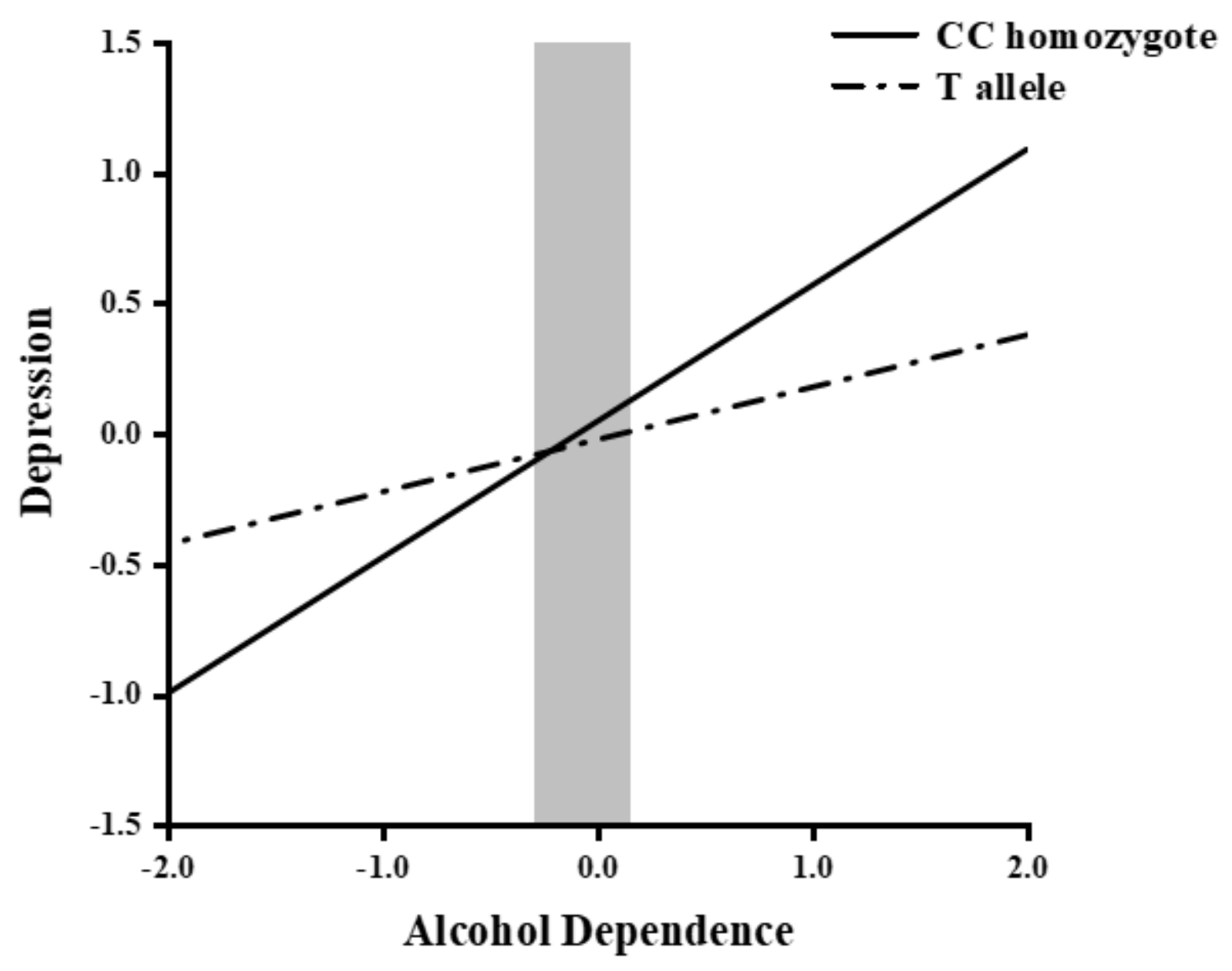

Figure 1

Region of significance test on depression from alcohol dependence in NPY rs16147 allelic groups. Grey shaded area represents $95 \% \mathrm{Cl}$ of the crossover point $\mathrm{C}$ of the interaction on the alcohol dependence axis. $95 \% \mathrm{Cl}$ of $\mathrm{C}$ ranged from -0.29 to 0.15 .

\section{Supplementary Files}

This is a list of supplementary files associated with this preprint. Click to download.

- Supplementaryfile.xIsx 